\title{
LA PRAXIS LEGAL Y ETICA DE LA PUBLICIDAD EN EL PERU
}

\author{
Gabriela Bardales \\ M.A. ESAN. \\ Raquel Reinoso \\ M.A. ESAN
}

$\mathbf{E}$

$\mathrm{n}$ nuestro pais, la publicidad se ha desarrollado al influjo de la situación económica o política imperante, $y$ en el actual marco de liberalización de los mercados y de incremento de la competencia, está cobrando mayor relevancia como herramienta eficaz y directa para que las empresas hagan conocer sus productos a los consumidores.

Sin embargo, la verdadera libertad de elección del consumidor hace indispensable la existencia de información adecuada $y$ veraz, pues no elige libremente quien no dispone de todos los elementos para hacerlo o recibe información distorsionada.

Desde este punto de vista, la regulación de la publicidad es vital si se quiere garantizar que la competencia entre las empresas se circunscriba a prácticas que no vayan en perjuicio de los consumidores o de los competidores, y para ello es necesario observar la práctica publicitaria de las empre- sas anunciadoras, pues el grado de regulación dependerá del grado de madurez alcanzado, no sólo por el mercado, sino también por las empresas que lo integran.

$\mathrm{El}$ presente trabajo describe $\mathrm{y}$ analiza la evolución de la reglamentación de la publicidad en el Perú, desde el Decreto Supremo $\mathrm{N}^{\circ}$ 003-74-OCI, emitido durante el gobierno del general Juan Velasco, hasta la actualidad. Examina también el papel de los organismos encargados de hacer cumplir las leyes relacionadas con la práctica publicitaria, la tipificación de los delitos en que se incurre y los esfuerzos de autorregulación realizados. Sintetiza la casuísticaderivadade las limitaciones planteadas por la legislación y, finalmente, revisa algunas de las principales disposiciones sobre publicidad existentes en Estados Unidos y la Comunidad Europea, de modo que se pueda apreciar las diferencias y el papel que en éstas correspónde a aspectos como la cultura, la percepción de lo moral y la libertad de expresión. 
1. Definición e importancia de la publicidad comercial

Según el Decreto Supremo $\mathrm{N}^{\circ}$ 002-8IOCLOAJ, la publicidad comercial se define como toda forma de presentación o información pagada acerea de las características o cualidades de un determinado bien o servicio que se realiza a través de los medios de comunicación masiva, tales como:

\section{Audibles y audiovisuales \\ - Radio \\ - Televisión \\ - Cine \\ - Electrónicos}

Impresos (gráficos)

- Periódicos

- Revistas

- Afiches

- Letreros exteriores

- Otros impresos

La publicidad busca establecer vínculos con individuos o grupos de individuos e influir sobre ellos con el fin último de vender un producto, un servicio o una idea: no obstante, cumple diversas funciones:

Respecto de las empresas:

- Promover la venta del producto o servicio.

- Reducir el espacio de las empresas competidoras en el mercado.

- Promover el prestigio de la empresa.

Respecto de los consumidores:

- Informar.

- Persuadir.

Respecto del sistema cconómico:

- Permitir al consumidor la libre elección de bienes entre opciones diversas.

- Ayudar a definir el mercado de acuerdo con las creencias y necesidades que inculque al público.

\section{Historia de la regulación publicitaria en el Perú}

\subsection{Promulgación de la primera norma legal: la dictadura}

La regulación jurídica más completa sobre publicidad en el Perú la constituye el Decreto Supremo $\mathrm{N}^{\circ}$ 003-74-OCI del 12 de noviembre de 1974, promulgado durante la dictadura del general Juan Velasco Alvarado y cuyo objetivo fue: "...asegurar que la publicidad en el país sea empleada en armonía con el Plan Nacional de Desarrollo". La Oficina Central de Información, $\mathrm{OCI}$, creada por ese gobicrno, tenía, entre otras, la finalidad de normar, orientar y controlar la publicidad en el pais, para lo cual contaba con un órgano específico: la Dirccción General de Publicidad.

De carácter normativo y con una clara orientación, este decreto supremo fue el primer documento legal en definir conceptos claves propios de la publicidad, como los tipos y formas de publicidad - publicidad comercial, publicidad indirecta, publicidad subliminal- $\mathrm{y}$ de medios de comunicación -visuales, audiovisuales y audibles-. Entre sus disposiciones más importantes destacamos las siguientes:

- La publicidad deberá estar en armonía con los intereses del desarrollo, la educación y la cultura peruanos.

- El contenido del mensaje publicitario comprende tanto lo que se dice, como la forma en que se presenta.

- La publicidad evitará usar motivaciones y patrones de consumo alienantes.

- La publicidad tenderá a promover el desarrollo de la producción nacional. 
- Los contenidos publicitarios deben ser veraces, verificables, respetuosos de la ética comercial y evitarán referencias a cualquier similar en el mercado (el resaltado es nuestro).

- La publicidad que incluya precios de venta deberá consignar el monto al contado y el de la financiación por separado cuando el bien o servicio se ofrezca a plazos; o en todo caso, valores al contado y a plazos simultáneamente.

-La publicidad que presente, informe o promueva la utilización o compra-ventade bienes o servicios que no estén disponibles en el mercado al momento del inicio de la publicidad, deberá previamente ser autorizada por el ministerio del sector corespondiente. Las promociones de este tipo no podrán mostrar ambientes y elementos que no les pertenezcan.

- La publicidad no utilizará procedimientos engañosos, tales como falsos descuentos, comparaciones con precios falsos o exagerados y otros.

- Las aseveraciones sobre cualidades y/o condiciones de un bien o servicio dentro de un mensaje publicitario deben ser verificables y respaldadas con pruebas solventes que las certifiquen.

- La publicidad no se hará difundiendo desventajas de los bienes o servicios de otras empresas o de su forma de hacer negocios, ni desacreditándolos frente al público.

- I a publicidad deberá presentar modelos constructivos de conducta humana. No podra difundirse publicidad que en su totalidad o en parte sea obscena, grosera, ofensiva a la dignidad humana o discrimi- natoria por razones de raza, sexo, condición social, retigión, nivel cultural, situación económica o defecto físico. No se utilizará representaciones o palabras que de alguna manera ridiculicen, denigren o atenten contra la moral y las buenas costumbres.

- Eíl lenguaje que se utilice en publicidad deberá ser correcto. No se podrá utilizar expresiones que disminuyan su nivel vulgarizándolo y atentando contra la cultura del pueblo peruano. Se evitará el uso de extranjerismos.

- Los mensajes publicitarios se deberán propalar en idioma castellano o en lenguas vernáculas, quedando prohibida la publicidad en idioma extranjero (el resaltado es nuestro).

- No están permitidas las imitaciones o copias de campañas publicitarias vigentes de otros anunciantes.

- La publicidad no utilizará logotipos o referencias de entidades del sector público nacional o privadas, sin previa autorización de éstas.

- La publicidad no hará explotación emocional de festividades conmemorativas o efemérides de exaltación de valores nacionales para promover la venta de bienes o servicios.

- La producción publicitaria deberá ser realizada exclusivamente en el pais, participando en ella sólo los residentes en el Perí (el resaltado es nuestro).

- Los mensajes publicitarios en los que aparezcan personas, las presentaran como personajes propios de la realidad nacio. nal (el resaltado es nuestro). 
- Todos los comerciales determinarán si los bienes o servicios publicitados son de manufactura nacional y/o elaborados con insumos nacionales, a fin de formar conciencia de muestra producción y realzar el esfuerzo de los trabajadores peruanos (el resaltado es nuestro).

- La publicidad que promueva la venta de articulos de uso intimo propios del hombre o de la mujer, no usarán a éstos como modelos.

- La publicidad tenderá a proporcionar en su presentación, según corresponda, vistas o películas en las que se pueda apreciar las diferentes regiones geográficas del pais.

- La publicidad de cigarrillos y bebidas con alto contenido alcoholico deberá ser presentada en un marco de buen gusto y discreción. De ninguna manera será presentado su consumo como hábito saludable y en el caso de los cigarrillos deberá señalarse que dicho consumo puede ser dañino para la salud.

- Se prohibe la participación de niños en publicidad, salvo en los casos en que se anuncien productos para uso exclusivo de éstos.

Como se desprende de los enunciados anteriores, el Decreto Supremo $N^{\circ}$ 003-74$\mathrm{OCI}$ estaba fuertemente orientado a fomentar la valoración de las costumbres y de los productos peruanos y el uso de nuestro idioma, es decir, a crear conciencia de "lo nuestro", característica que estuvo presente en todas las acciones del gobierno de entonces. Sin embargo, este cargado enfasis nacionalista se mantuvo en la legislación posterior, tal como se verá a continuación.

\subsection{La regulación publicitaria y el re- greso a la democracia}

Restablecida la democracia en el país, el 21 de abril de 1981 se aprobó el Decreto Supremo $N^{\circ}$ 002-81-OCI/OAJ, que pretendió, sin lograrlo, marcar distancias con la norma anterior. En efecto, la mayor parte del articulado de este decreto respetaba los enunciados originales de su antecesora y mantenía un serie de restricciones. Se prohibía, por cjemplo, utilizar testimonies de supuestos téenicos o profesionales para recomendar el consumoo la venta de un determinado bien o servicio; también la publicidad indirecta en prácticamente todos los medios: televisión, cine, radio y medios gráficos.

No obstante, algunas disposiciones moderaron las limitaciones originales. Por ejemplo, aunque se seguía exigiendo el uso del lenguaje correcto y se desterraban las expresiones que disminuyeran su nivel o lo vulgarizaran, se permitía, por excepción, el uso de modismos y giros populares en los casos en los que los personajes osituaciones típicas lo requirieran.

Continuaban las prohibiciones asociadas a la nacionalidad de la producción y de las personas intervinientes. La producción publicitaria debía ser realizada en el país y sólo se permitía la participación en ella de peruanos y extranjeros residentes en el Perú. Pero, siempre por excepción, se autorizaba la utilización de ambientes, personajes o recursos técnicos no disponibles en el país, siempre que fueran integrados minoritariamente en las piezas publicitarias:

También se permitía la participación de menores en publicidad si se los presentaba de acuerdo con su edad o con la 
edad que representaran, $\mathrm{y}$ sujeta a las disposiciones legales entonces vigentes.

En cuanto a las normas operativas para los medios audibles $y$ audiovisuales que este dispositivo contenía, destacan las siguientes:

- La publicidad de cigarrillos y bebidas con alto contenido alcohólico sólo se permitía después de las 21:00 horas.

- Se fijaba en 12 minutos el tiempo máximo de publicidad en radio y televisión por cada hora de transmisión.

En el caso de transmisiones directas de espectáculos deportivos, no se permitía la interrupción del normal desenvolvimiento de las acciones para insertar tandas comerciales.

- La proyección de publicidad comercial en las salas de exhibición cinematográfica de todo el país se limitaba a cinco minutos en el intermedio, con excepción de la que se refería a las obras en exhibición o por exhibirse.

- Todo publirreportaje debía ser identificado como tal, mediante orla, leyenda, número u otro medio.

\subsection{Regulación actual}

\section{Normas legales}

Diez años después, el tema de la supervisión publicitaria cobró nueva actualidad al expedirse el Decreto Legislativo $\mathrm{N}^{*} 691$. del 6 de noviembre de 1991, por medio del cual, además, se derogaban los decretos supremos $\mathrm{N}^{\circ} 002-81$-OCI/OAJ (21.04.81), $\mathrm{N}^{\circ}$ 007-85-COMS (19.7.85), $\mathrm{N}^{\circ}$ 026-90ICTL/IND (11.09.90) y todas las otras nor- mas que se le opusieran.

Las principales normas generales contenidas en este dispositivo son las siguientes:

Ningún anuncio debe favorecer o es. timular cualquier clase de ofensa o discriminación racial, sexual, social, política o religiosa; tampoco contener algo que pue$\mathrm{da}$ inducir a actividades antisociales, criminales o ilegales o que parezca apoyar, enaltecer o estimular tales actividades.

- Los anuncios no deben contener informaciones ni imágenes que directa o indirectamente, o por omisión, ambigüedad o exageración, puedan inducir a error al consumidor, especialmente en cuanto a las características, precio y condiciones de venta del producto.

- Todo anuncio debe respetar la libre y leal competencia mercantil.

- Es lícito hacer comparaciones expresas de productos, incluyendo lo relativo a precios, si la comparación no denigra a los competidores ni confunde a los consumidores. Toda comparación debe ser especifica, veraz y objetiva y dar una apreciación de conjunto de los principales aspectos de los productos comparados.

- Los anuncios deben distinguirse claramente como tales, cualquiera sea su forma y el medio empleado para su difusión. Siempre que una agencia de publicidad o un publicitario realice un anuncio, debe colocar en el mismo su nombre, logotipo, o cualquier otro tipo de signo que permita su clara identificación.

- Los anuncios de cigarrillos y demás productos del tabaco deben incluir en for- 
ma expresa y con claridad suficiente la frasc "Fumar puede ser đañino para la salud".

- Tratándose del contenido de los anuncios, se considera responsable a la persona natural o jurídica anunciante. En el caso de las normas de difusión será responsable el titular del medio de comunicación social.

- Por ser la publicidad un servicio profesional, existe responsabilidad solidaria entre cl anunciante y la agencia de publicidad, o quien haya elaborado el anuncio, cuando la infracción se encuentre en un contenido publicitario distinto de las características propias del producto anunciado.

Cualquier ilustración, descripción o afirmación publicitaria sobre el producto anunciado scrá siempre susceptible de prueba por el anunciante, en cualquier momento y sin dilación, a requerimiento del Conasup, de oficio o a pedido de parte.

Debe mencionarse que estas normas sobre publicidad guardan coherencia con lo establecido en la norma de protección a los consumidores (Decreto Legislativo $\mathrm{N}^{\circ}$ 716), en la que especificamente se determina el derecho de los consumidores a: "...recibir de los proveedores toda la información necesaria para tomar una decisión o realizar una elección adecuadamente informada en la adquisición de productos y servicios".

\section{Organismos de control}

Otra medida no menos importante del Decreto Legislativo $\mathrm{N}^{\circ} 691$ fue la creación (Artículo 26 $6^{\circ}$ del Consejo Nacional de Supervisión de la Publicidad, Conasup, como un organismo autónomo y descentralizado del Sector Industria, Comercio Interior, Turismo e Integración, encargado de prevenir y sancionar la publicidad ilícita, incluyendo en su estructura a todos los sectores involucrados en la actividad publicitaria, es decir: representantes del Estado (2), de los empresarios anunciantes y publicistas (2) y de los consumidores (2).

De este modo, el papel protagónico se traslado a la actividad privada, cerrándose así una etapa en la que las denuncias referidas a la publicidad se ventilaban en organismos incompetentes (Inacoso, Sinacoso, y Conacul), donde la ausencia de especialistas propiciaba toda clase de malinterpretaciones $\mathrm{e}$ injusticias.

No obstante, el Conasup tuvo una vigencia muy breve. $\Lambda$ fines de noviembre de 1992, el gobicrno creó (Decreto Ley $\mathrm{N}^{e}$ 25868) el Instituto Nacional de Defensa de la Competencia y de la Protección de la Propiedad Intelectual, más conocido por sus siglas: Indecopi. Encargado de aplicar las normas que regulan la competencia mercantil, la propiedad intelectual y la calidad de los productos, este organismo está estructurado sobre la base de comisiones $y$ oficinas que resuelven en primera instancia. Una de éstas es la Comisión $\mathrm{Na}$ cional de Supervisión de la Publicidad, que asume las funciones que antes cran de competencia del Consejo Nacional de Supervisión de la Publicidad (curiosamente, las siglas del máximo organismo de control de la publicidad se mantienen: Conasup). Además el Indecopi cuenta con el Tribunal de Defensa de la Competencia y de la Propiedad Intelectual, que resuelve en segunda y última instancia.

En la actualidad, el Indecopi se ocupa de aplicar las normas sobre libre compe- 
tencia, que comprende: evitar los monopolios, los controles y las restricciones, fiscalizar el dumping y los subsidios, supervisar la protección al consumidor y la publicidad comercial, reprimir la competencia desleal, supervisar las normas técnicas, la metrologí, el control de calidad y las restricciones paraarancelarias, supervisar las normas de acceso y salida del mercado, en especial la reestructuración de empresas (disolución, liquidación y quiebra).

También está encargado de proteger la propiedad intelectual y la propiedad industrial. En el caso de esta última debe aplicar las normas sobre patentes de invención, modelos de utilidad, secretos de producción, diseños industriales, marcas, nombres comerciales, eslóganes publicitarios y denominaciones de origen.

Cabe resaltar que la creación del Indecopi obedeció al propósito de centralizar las distintas funciones que el Estado debe ejercer en una economía de mercado para preservar la estabilidad funcional de la libre competencia y, de esta manera, climinar la duplicación de criterios $y$ de costos en el ejercicio de las funciones públicas. Sin embargo, en opinión de un estudioso del tema, el doctor Fernando Raventós", este objetivo inicial se ha ido abandonando. Primero, porqueel Indecopi no tiene competencia sobre todo lo referido a las operaciones de márketing de las empresas. Las promociones de ventas, por ejemplo, intensivamente utilizadas en los programas actuales de mercadco de las empresas, aún deben ser autorizadas por el Ministerio del Interior o la municipalidad

1/ Femando Raventos Marcos, "El Indecopi: $z$ todo para uno $y$ uno para todo?", $1 / 2$ de Márketing. Lima, 7(74): 9, feb, 1993. correspondiente, según sea el caso. En segundo lugar, porque el Indecopi ha terminado absorbiendo todas aquellas funciones del sector industria o comercio de las cuales el Estado no ha podido deshacerse a pesar de todas las reestructuraciones y reorganizaciones realizadas.

Según el doctor Raventós, en el caso especifico del control publicitario, el Indecopi ha significado una regresión en materia de participación ciudadana ỳ democratización, pues el Gobierno ha reasumido totalmente el poder de decisión. No obstante, esta última crítica ha sido refutada por los miembros del comité consultivo de Indecopi ${ }^{2}$, quienes han sacado a relucir la representación que ahora tiene el sector privado no sólo en la designación de las comisiones, sino también en el tributnal que constituye la segunda instancia.

\subsection{La regulación publicitaria y los gre- mios $^{2}$}

Paralelamente al recuento de los dispositivos oficiales dictados para regular la actividad publicitaria en el pais, es necesario referirse a las asociaciones que los profesionales, empresas y entidades involucradas en este quehacer han creado para proteger sus intereses.

Las agencias de publicidad fueron las primeras en organizarse. La Asociación Peruanade $\Lambda$ gencias de Publicidad, APAP, se fundó en 1954 básicamente con el fin

2/ Alfredo Bullard G., "El Indecopi no es cajón de sastre", 1/2 de Marketing. Lima, 7(75): 21-22. mar., 1993.

3/ Esta sección está hacada en el artículo: Femando Raventos, "La publicidad y sus gremios". I/2 de Marketing. Lima, 4(47): 11-12, nov, 1990. 
de difundir la publicidad, pues entonces todavía no existía la televisión en el país. Esta asociación ha realizado un intenso trabajo en lo que a normatividad se refiere, tanto a nivel de regulación jurídica como de autorregulación.

En cuanto a la regulación jurídica, cabe resaltar que gracias al trabajo realizado por la APAP se dictaron las primeras normas oficiales en el país. Durante el gobierno militar, en 1974, la APAP elaboró y presentó un proyecto que luego los militares desnaturalizaron con la promulgación del D.S. $\mathrm{N}^{\circ}$ 003-74-OCI. No obstante, este proyecto fue retomado durante el segundo gobierno del presidente Belaunde y aprobado mediante el D.S. $\mathrm{N}^{\circ}$ 002-81-OCI/DAJ, que estuvo vigente hasta 1991.

Con respecto a la autorregulación, la APAP adoptó los denominados Códigos de Etica y Creativo, y después fundó, con el resto del gremio publicitario, el Consejo Nacional de Publicidad, Conapu, como órgano de autorregulación gremial.

El resto de gremios vinculados a la publicidad siguió el ejemplo de las agencias; el panorama actual de la autorregulación publicitaria prácticamente terminó de configurarse durante los años ochenta.

LaAsociación de Publicitarios del Perú, APP, se fundó en 1978 con la intención de promover la capacitación profesional de sus asociados.

En 1980 se fundó la Asociación de Realizadores de Comerciales de Cine y de Televisión, ARCO, principalmente para defender la producción nacional. Su desarrollo estuvo estrechamente ligado a la prohibición de difundir por televisión publicidad producida en el exterior. Fue por presión de la ARCO que el presidente Belaunde decidió aplicar las normas de publicidad dictadas por su gobierno dos años antes. Luego se constató que las normas de publicidad dadas con la intención de proteger a los consumidores, sirvieron más para proteger a los productores nacionales.

En 1984 toc6 el turno a los anunciantes, que formaron la Asociación de Anunciantes del Perú, AAP, para realizar acciones conjuntas que les permitiera optimar sus inversiones publicitarias.

Finalmente, en 1986 todos estos gremios vieron la necesidad de unir sus esfuerzos y acordaron crear un mecanismo de autorregulación privado. El año anterior el Partido Aprista llegó al poder y sus autoridades dejaron entrever que encargarian el control de la publicidad al Ministerio de Educación. Frente a estas circunstancias nació el Consejo Nacional de Publicidad, CONAPU, cuyas fundadoras fueron las asociaciones gremiales representantes de agencias, anunciantes y publicitarias. Después se les sumó la asociación de productores de comerciales.

La intención de este consejo era funcionar como un organismo de autorregulación tomando como base un código de ética publicitaria y, a la vez, prestar apoyo técnico a los organismos estatales en materia de control de la publicidad, como un órgano consultor. Sin embargo, en la práctica este consejo ha funcionado sólo de manera parcial.

Finalmente, en 1987 se constituyó oficialmente el capítulo peruano de la International Advertising Association, IAA, or- 
ganismo mundial que agrupa a 70 paises y cuyo objetivo básico es la defensa de la libre información al interior de los mercados. Su oficina central está en New York.

\section{La puesta en práctica de la regu- lación}

\subsection{Procedimientos, responsabilida- des y sanciones}

Dado el carácter público de las infracciones a las normas de publicidad, cualquier persona está facultada a interponer una denuncia. No es necesario acreditar haber sufrido un daño ni ser el directamente afectado por la publicidad en cuestión. Con el propósito de darle la mayor transparencia al proceso y la debida difusión a las resoluciones que crean precedentes importantes, las resoluciones emitidas por la Conasup son publicadas en el Diario Oficial El Peruano.

Presentada la denuncia, el proceso que sigue la Conasup consta de tres etapas:

Calificación de ladenuncia.-Etapa que consiste en la evaluación genérica de la denuncia.

Junta de conciliación.- Etapa previa al proceso propiamente dicho $\mathrm{y}$ durante la cual se busca que denunciante $y$ denunciado lleguen a un acuerdo (el plazo máximo es de cinco días).

Notificación de la denuncia y contestación.- Etapa con la cual se inicia formalmente el proceso, aunque la norma no ha dispuesto los requisitos para la contestación ni las formalidades que deben seguirse.

\section{Responsabilidades"}

Como en cualquier actividad humana, la publicidad genera responsabilidad para los que participan en ella: el anunciante, la agencia de publicidad y el medio de comunicación en que se difunde. El grado de responsabilidad de cada uno de estos agentes se especifica claramente en el Decreto Legislativo $\mathrm{N}^{\circ} 691$.

Se considera que el anunciante es el responsable directo del contenido publicitario del anuncio, pues se trata de "su" producto o de "su" servicio y, por lo tanto, tiene potestad para decidir. Teóricamente es el que en mejores condiciones está para establecer si las cualidades que se publicitan del producto corresponden o no a la realidad.

A la agencia de publicidad -o al publicitario- creadora del anuncio le corresponde asumir una responsabilidad solidaria, porque se presume que conoce el marco legal y sabe cómo debe presentar el producto para no incurrir en falta. Al respecto, hay que anotar que no siempre la agencia publicitaria está convenientemente informada de las características del producto. Algunas agencias no comprueban lo que el cliente afirma de su producto y se limitan a seguir sus indicaciones.

Con relación al medio de comunicación, es lógico admitir que no se le pueda exigir comprobar la veracidad de cada uno de los anuncios que transmite; esto sería extremadamente difícil y costoso. Por

4/ Esta sección está bacada en: Jaime Delgado y Crisologo Caceres, Publicidad; rtgimen juridico yprictica comercial, Lima, Instituto de Dere. chos del Consumidor, 1993, Capitulo 4: La responsabilidad. 
ello, la ley considera que el medio sólo puede ser responsable en los casos de violación de las normas de difusión establecidas.

\section{Sanciones"}

La ley establece cuatro tipos de sanciones: amonestación, multa, cesación del anuncio y rectificación publicitaria.

La amonestación es la sanción más leve y consiste en una llamada de atención de la Conasup a la infractora para que en el futuro no repita la actuación publicitaria ilegal materia de la denuncia.

La multa es una medida de orden pecuniario. Los fondos generados por este concepto se destinan al Tesoro Público.

La cesación del anuncio tiene por finalidad interrumpir la campaña cuestionada para evitar que siga perjudicando al público y distorsionando el mercado.

Por su parte, la rectificación publicitaria busca erradicar el efecto residual de la publicidad engañosa, basándose en una proyección al futuro. Ayuda a restituir su lugar en el mercado a los competidores leales. La severidad de esta sanción intenta desalentar la proliferación de anuncios falsos y contribuye a evitar que el anuncianteobtenga ganancias ilicitas posteriores, fruto de su actuación desleal previa.

5/ Esta sección está basada en: Delgado y Cáceres, Op. Cit. Capitulo 6: Sanciones.

\subsection{Criterios básicos de la actual legisla- ción ${ }^{N}$}

El Código Internacional de Práctica Publicitaria de la Cámara Internacional de Comercio, CIC, establece los siguientes princípios básicos para la elaboración de anuncios publicitarios:

Toda publicidad deberá ser lícita, decente, honesta y verdadera.

- Los anuncios deberán ser elaborados con el debido sentido de responsabilidad social y deberán respetar los principios de la leal competencia generalmente aceptados en los negocios.

- Los anuncios no deberán defraudar la contianza del público en la publicidad.

De estos principios se han derivado los criterios con los cuales juzgar los anuncios publicitarios, los que también son recogidos por nuestra actual legislación.

El primero de estos criterios es la buena fe publicitaria, que implica confianza y honestidad y se traduce en acatar las normas sin valerse de argucias.

El segundo criterio es el examen superficial del anuncio, según el cual todo anuncio debe ser juzgado por la apreciación que una persona común y corriente pueda hacer de él después de una rápida observación.

El tercer criterio es la indivisibilidad del anuncio, según el cual, para juzgar un anuncio es necesario apreciarlo como un

6. Esta seccib́n está basada en: Delgado y Cáceres, Op. Cit., Capitulo 1: Aspectos generales. 
todo, es decir, observar el efecto que causa el conjunto de sus elementos.

\subsection{La labor realizada por la Conasup}

Desde su creación hasta febrero de 1994. la Conasup ha atendido alrededor de trescientas cincuenta denuncias, lo que ha proporcionado a sus miembros una valiosa experiencia y enriquecido el tratamiento técnico del tema de la regulación de la publicidad. Sin embargo, todavia no se han perfeccionado los procedimientos para el tratamiento de los casos, $y$ las deficiencias del proceso han obligado muchas veces a la Conasup a reconsiderar sus fallos. Se observa también cierta indecisión para aplicar las sanciones dictaminadas, pues se aceptan los recursos de apelación o impugnación y se postergan las decisiones finales-a veces indefinidamente-, enviando las causas a la segunda instancia.

Con relación a los usuarios, un seguimiento de los casos presentados permite apreciar que hay un gran desconocimiento acerca de la legislación vigente en materia publicitaria entre los abogados de las empresas denunciadas; desconocimiento que algunas veces es mayor en lo que respecta a las agencias de publicidad". Y esto a pesar de que la Conasup trata de difundir permanentemente el marco legal entre las empresas anunciantes, las agencias de publicidad $\mathrm{y}$ las personas interesadas.

El siguiente cuadro muestra el estado en que se encuentran los casos denunciados hasta febrero de 1994.

En la siguiente página se presentan otros dos cuadros para ilustrar al lector

1/ 1/2 de Marketing. Lima, 6(71):3, (71), nov.. 1992. acerca de la naturaleza de las denuncias recibidas y el tipo de resoluciones que se emiten, respectivamente.

ESTADO DE LAS DENUNCIAS PRESENTADAS ANTE LA CONASUP

\begin{tabular}{|lr|}
\hline Estado de las Denuncias & Número \\
\hline Resueltas en Junta de Conciliación & 51 \\
Resueltas en Tribunal & 181 \\
Denuncia abandonada o anulada & 25 \\
No hay más información o & \\
no concluye & 71 \\
Acreditó información requerida & 12 \\
No admitida & 4 \\
Suspensión voluntaria & 4 \\
\hline
\end{tabular}

Fuente: Archivo de la Conasup.

Elaboración propia.

4. Manifestaciones ilícitas de la publicidad $^{\mathrm{N}}$

En este acápite se describe algunas de las múltiples formas en que la publicidad puede causar perjuicio tanto al consumidor como a los competidores y al mercado en general; prácticas que son reguladas por el Decreto Legislativo $\mathrm{N}^{\circ} 691$.

\subsection{Publicidad abusiva}

En el Código de Defensa del Consumidor del Brasil se define la publicidad abusiva de la siguiente manera:

Es abusiva, entre otras, la publicidad discriminatoria de eualquier naturaleza, la que incite a la violencia, explote el miedoo

8 Esta seoción cstá bacada en: Delgado y Cáceres, Op. Cit., Capitulo 2: Manifestaciones illicitas de la publicidad. 
NATURALEZA DE LAS DENUNCIAS

\begin{tabular}{|l|l|l|}
\hline \multicolumn{1}{|c|}{ Denunciante } & \multicolumn{1}{|c|}{ Denunciadas } & \multicolumn{1}{c|}{ Detalle } \\
\hline De oficio & $\begin{array}{l}\text { Escuela Superior de Administración } \\
\text { Ejecutiva Staff, Instituto Raymond } \\
\text { Barre, Instituto JoséLuis Bustamante } \\
\text { y Rivero (Arequipa) e Instituto Su- } \\
\text { perior Tecoológico Data Pro. }\end{array}$ & $\begin{array}{l}\text { Por alegaren sus avisos un aivel compatible } \\
\text { con niveles universitarios. }\end{array}$ \\
\hline Celluphone S.A. & Fotocell S.A. & $\begin{array}{l}\text { Por publicidad denigratoria cn un anuncio } \\
\text { de la denunciada donde felicita al Indecopi } \\
\text { por resolver el caso a su favor, cuando los } \\
\text { procedimientos aún no habian sido termi- } \\
\text { nados. }\end{array}$ \\
\hline Conasev & $\begin{array}{l}\text { Consorcio Peruano de Aborto } \\
\text { Previo y Maxiplán. } \\
\text { Tracker S.A. }\end{array}$ & $\begin{array}{l}\text { Pornomencionar claramenteque se tratade } \\
\text { Fondos Colectivos. } \\
\text { Omniagro. }\end{array}$ \\
\hline
\end{tabular}

Fuente: I/2 de Marketing, Lima, 7(91), jun., 1994, p. 16.

Elaboración propia.

RESOLUCIONES EMTTIDAS

\begin{tabular}{|c|c|c|}
\hline Denunciada & Caso & Resolución \\
\hline AFP EI Roble & $\begin{array}{l}\text { En un anuncio publicitario televisi- } \\
\text { voladenunciadahacia uso de imaige- } \\
\text { nes de pensionistas, quienes denun- } \\
\text { ciaron el becho. }\end{array}$ & $\begin{array}{l}\text { Cese definitivo del anuncio que utiliza las } \\
\text { imágenes de los pensionistas denuncian- } \\
\text { tes, así como de cualquier otro pensionista } \\
\text { identificable que no hubien otorgado auto- } \\
\text { rización expresa. }\end{array}$ \\
\hline Jorge Ferrand & $\begin{array}{l}\text { El denunciado propala a travts de la } \\
\text { radio un anuncio que contiene la } \\
\text { afirmaeion "De nuevo?, Inol: en oc- } \\
\text { tubre, la voz es John Secada". En la } \\
\text { primera parte del spot se escuchaba } \\
\text { cantar a Ricardo Arjona. }\end{array}$ & Cese defin \\
\hline Chifa Jumbo S.A. & $\begin{array}{l}\text { Chifa Jumbo S. A. difundió un anun- } \\
\text { cio en diversos canales de televisión } \\
\text { en el que utilizaba el lema comercial } \\
\text { de Chifast S.A. acompañado del si- } \\
\text { guiente diálogo: "Te voy a invitar un } \\
\text { chifa que te encantala". y el } \\
\text { interlocutor respondia: "No, yo si te } \\
\text { voy a invitar a un chifa verdadero". }\end{array}$ & $\begin{array}{l}\text { Se ordeno a Chifa Jumbo S.A. el oese } \\
\text { definitivo de la afirmación "Te encantala", } \\
\text { por cuanto el anuncio denigra a CHIFAST } \\
\text { S.A. al dar a entender que su comida no } \\
\text { constituye chifa de verdad, asf como por } \\
\text { utilizar un lema comereial registrado. } \\
\text { Se sanciono con multa de dos UIT (unida. } \\
\text { des impositivas tributarias) la infracción a } \\
\text { los articulos } 3 \text { y } 7 \text { del Decreto Leg. } \mathrm{N}^{\circ} 691 \text {. }\end{array}$ \\
\hline
\end{tabular}

Fuente: $1 / 2$ de Márketing. Lima, 7(98), oct., 1994, p. 25.

Boletín Indecopi, Lima, 2(11), dic, 1994.

Elaboración propia. 
la superstición, se aproveche de la deficiencia de juicio y experiencia del niño, no respete los valores ambientales o sea capaz. de inducir al consumidor a comportarse de forma perjudicial o peligrosa para su salud y seguridad".

A partir de esta definición, se pucde decir que un anuncio es abusivo cuando constituye un atentado contra las reglas de conducta o los valores normalmente aceptados. Pero conceptos como éstos causan gran dificultad, porque si bien son fáciles de entender, son muy difíciles de precisar y, más aun, de aplicar a casos concretos.

La discusión de los estatutos del Grupo de Trabajo del Instituto Nacional de Publicidad, de España, aporta otras consideraciones:

(..) la publicidad no ha de faltar al buen gusto, al decoro y decencia sociales o a los sentimientos del público. No es lícita, porlo tanto, aquella publicidad que implique menosprecio o descrédito de la cultura y sus bienes espirituales o materiales, y debe además respetar el idioma evitando expresiones soeces, groseras y vulgares ${ }^{\mathrm{to}}$.

Sin embargo, debe tenerse en cuenta el carácter variable de las calificaciones que los hechos pueden recibir de acuerdo con este tipo de categorías. Algo censurable hoy, puede resultar socialmente aceptable después de un tiempo.

El concepto de publicidad abusiva incluye la llamada publicidad antisocial, es decir, aquella que contraviene de alguna manera las normas y valores de conducta social vigentes en una comunidad.

y/ Citado por Delgado y Cáceres, Op. Cit., p. 42.

10/ Citado por Delgado y Cáceres, Op. Cit.. p. 43.
Como ejemplo de este tipo de publicidad se puede mencionar un anuncio televisivo de los chocolates "Mad" transmitido hace algunos años en el Perú. El spot mostraba a una joven pareja paseando de noche en un auto deportivo por los suburbios de la ciudad. De repente, el muchacho detenía su vehículo en una csquina donde se encontraba parado otro joven quien, con gesto cómplice, le scñalaba un lugar en la penumbra cercana. El protagonista descendía del auto y se introducía en un oscuro callejón donde, por una ventanilla entreabicrta, le entregaban un paquete a cambio de dinero. Al llegar a su auto, el joven descubría el contenido del paquete y mostraba simplemente un chocolote "Mad". Presentar como algo natural y propio de la juventud un hecho rodeado por la atmósfera de misterio y transgresión de la lcy que normalmente se asocia con cl accionar de los compradores de droga, podía interpretarse como que se estaba propiciando el consumo de sustancias prohibidas como actitud correcta para los jóvenes.

Otro caso susceptible de ser calificado como de publicidad antisocial fue el siguiente anuncio de una marca de gallctas. A una niña le preguntahan si estaba comiendo galletas, y ella, con la boca llena de éstas, movía la cabeza en señal de negación. El hecho incentivaba a la mentira como algo normal y aceptado ${ }^{\mathrm{t}}$.

También se han presentado comerciales en los que aparecen niñas y niños vestidos como pandilleros y pintarrajeando las paredes de lugares públicos, como si ésta fuera una conducta apropiada.

I1/ Maritza Reítegui, "I a publicidad, la ética y la violencia", $17.65 \%$ :medias, publicidad, mairkering. Lima, 5(68): 4-7, may, 1994, p. 7. 
Según algunos publicistas, no se les debería prohibir la producción de escenas como éstas, pues sólo reflejan la vida real. No obstante, a ellos podría respondéseles así:

"(...) en la sociedad hay muchas lacras que deberian ser desterradas: narcotrafico, terrorismo, etc., y no hay justificación para que la publicidad presente estos hechos como normales, deseables e incluso cotidianos, cuando en realidad el sentimiento colectivo los repudia y, más bien, busca desterrarlos para siempre" ${ }^{n 12}$.

La publicidad sexista, esto es, la actitud discriminatoria por causa del sexo, constituye una de las formas más frecuentes de publicidad abusiva; y el machismo, que considera al sexo masculino superior al femenino, es quizá el mejor ejemplo de sexismo.

Una muy clara definición de la publicidad sexista es la que ha elaborado una asociación feminista canadiense:

Es discriminatoria cualquier publicidad que ataque a la dignidad de las personas, representándolas en una situación de inferioridad o devaluándolas de alguna manera. Generalmente es al sexo femenino al que se pinta con mayor frecuencia de manera más desfavorable. Se puede decir, por este hecho, que la publicidad es sexista por la manera como devalúa un sexo en relación con el otro's.

Por otro lado, un grupo de especialistas en diversas materias convocado por el Consejo Sueco Nacional de Politicas del Consumidor, CSNPC, con el propósito de elaborar una propuesta de definición de

12/ Delgado y Cíceres, Op. Cit., p. 45.

13/ Citado por Delgado y Ciceres, Op. Cit., p. 47. publicidad sexista, estableció los siguientes criterios para ser tenidos en cuenta:

- La publicidad que usa a la mujer como objeto para llamar la atención.

- La publicidad que utiliza insinuaciones sexuales y promesas que son irrelevantes para el producto.

- La publicidad que da una idea falsa de la contribución de las mujeres o los hombres al trabajo.

- La publicidad que refuerza el estereotipo de los sexos en la sociedad.

- La publicidad que presenta uná visión estereotipada de los rasgos de personalidad de las mujeres y de los hombres.

- La publicidad dirigida a los niños que transmite impresiones falsas y pasadas de moda sobre lo que es característico de los hombres y de las mujeres.

Sin embargo, no es fácil determinar las situaciones de esta naturaleza, porque la presencia de la mujer o del hombre en un anuncio no siempre puede interpretarse como un acto de discriminación, una visión estereotipada o el uso de la persona como objeto sexual. En este último caso. la exhibición de los cuerpos -aun desnudosno es lo cuestionable, sino la forma como se utiliza su imagen.

Por ejemplo, una joven vestida provocativamente y sentada sobre el techo de un carro deportivo constituye evidentemente un caso que raya en lo ilícito, pues utiliza a la mujer como un objeto sexual para llamar la atención del usuario potencial del producto y "excitar" su deseo de poseerlo. Más clocuente -si puede serlo- 
es el anuncio de Toyota Hearne que presenta a una mujer "de la cintura para abajo" mientras va describiendo los atributos del carro, e incluso duplica la imagen cuando se refiere a los repuestos.

Otro caso de publicidad asociada a la atracción sexual es el eslogan de las camisas John Holden: "Prohibido para menores". Es decir, lo que la camisa puede hacer por el usuario al vestirlo es solo permisible a los adultos. Similar es el efecto que busca el jingle de la línea Old Spice en el que una hermosa mujer susurra: "Cuando mi hombre usa Old Spice todo puede suceder".

La explotación de estos recursos ha fomentado que ciertos scgmentos del público, principalmente mujeres, denuncien y se opongan fuertemente a este tipo de publicidad.

En cuanto a la formación de estercotipos, se puede observar que casi siempre la mujer es presentada como objeto sexual -como cn los ejemplos anteriores - o como la perfecta y eficiente ama de casa. Son frecuentes los anuncios que muestran a mujeres felices, sonrientes y con un muy cuidado aspecto físico, aunque sus niños estén destrozando la sala, ensuciándose en el jardín o causando destrozos en la cocina. Esta situación, obviamente, no pertenece a la realidad ${ }^{12}$.

\subsection{Publicidad engañosa}

La publicidad engañosa es una de las manifestaciones ilícitas más frecuentes de la publicidad y quizás la más dañina para el público, pues muchas veces éste decidesus

14/ Reattegui Valdivieso, Op. Cit.,p. 6. compras basándose únicamente en los anuncios de los productos o servicios y corre el riesgo de ser engañado.

La legislación peruana define la publicidad engañosa en varios dispositivos. Una primera definición se encuentra en el Artículo $4^{\circ}$ del Decreto Legislativo $\mathrm{N}^{\circ}$ 691; otra complementaria aparece en el Artículo $15^{\circ}$ del Decreto Legislativo $\mathrm{N}^{\circ}$ 716: Normas de Protección al Consumidor.

También se refieren a este tipo de publicidad ilícita los artículos $238^{\circ}$ y $239^{\circ} \mathrm{del}$ Código Penal y el Artículo $9^{\circ}$ de la Ley sobre Represión de la Competencia Desleal -en esta última con la denominación de Actos de Engaño-.

Para determinar si una publicidad es engañosa debe tenerse en cuenta todos sus elementos, principalmente los concernientes a:

- Las características de los bienes o servicios anunciados, tales como disponibilidad, naturaleza, ejecución, composición, procedimiento, fecha de expiración. especificaciones técnicas, entre otras.

- El precio o su modo de fijación, y las condiciones de suministro de los bienes o de prestación de los servicios.

- La naturaleza, las características y los derechos del anunciante, tales como identidad, patrimonio, calificaciones y derechos de propiedad industrial, comercial o intelectual, y los premios o distinciones que haya recibido.

Aunque el engaño puede revestir innumerables formas, éstas pueden agruparse en básicamente tres modalidades: las pre- 